\title{
3 COMPETÊNCIAS EMOCIONAIS E PREVENÇÃO DO ABANDONO NOS ESTUDANTES DO ENSINO SUPERIOR POLITÉCNICO
}

\author{
| Manuela Ferreira ${ }^{1}$; João Duarte²; Ana Paula Cardoso3; Lídia Cabral'; ; Raquel Guiné5; Sofia Campos ${ }^{6}$; Cândida Alves $\mid$
}

\section{RESUMO}

CONTEXTO: Nos últimos anos, a comunidade científica foi tomando consciência da importância do desenvolvimento de competências emocionais para o sucesso escolar e profissional dos estudantes.

OBJETIVO(S): Identificar os fatores que influenciam o abandono escolar dos estudantes do ensino superior politécnico. Analisar a relação entre as competências emocionais e o abandono escolar dos estudantes do Ensino Superior Politécnico.

METODOLOGIA: Estudo quantitativo, transversal, descritivo e correlacional. O instrumento de recolha de dados utilizado foi questionário de caracterização sociodemográfica dos estudantes e dos pais, a Escala de Motivos para Abandono do Ensino Superior (Ambiel, 2015) e a Escala Competências Emocionais (Taksic', 2000), adaptada para Portugal por Faria e Santos (2006). Amostra constituída por 560 estudantes do ensino superior a frequentarem o $1 .^{\circ}$ ano do curso.

RESULTADOS: Participaram 560 estudantes do ensino superior a frequentarem o $1 .^{\circ}$ ano do curso, maioritariamente feminina (69,3\%), com uma idade mínima de 18 anos e uma máxima de 30 anos, correspondendo-lhe uma média de 19,76 anos ( $\pm 2,06$ anos), 36,6\% da área da tecnologia. O sexo influenciou o abandono escolar dos estudantes do ensino superior, sendo os estudantes do sexo feminino os que revelam mais motivos para $\mathrm{o}$ abandono $(\mathrm{p}=0,010)$. Os estudantes cujas mães se encontram ativas profissionalmente manifestam mais Intenção de abandono $(\mathrm{p}=0,035)$. A perceção emocional, a expressão emocional e a capacidade de lidar com as emoções foram preditoras da intenção de abandono escolar.

CONCLUSÕES: Os resultados apontam para a necessidade de inclusão nos programas de intervenção contra o abandono escolar, das variáveis sexo, idade e algumas dimensões das competências emocionais, para minimizar, assim, as suas consequências, quer para os estudantes, quer para a própria sociedade.

\section{PALAVRAS-CHAVE: Competências emocionais; Prevenção do abandono; Estudantes do ensino superior}

\section{RESUMEN}

“Competencias emocionales y prevención del abandono en los estudiantes de enseñanza superior politécnico"

CONTEXTO: En los últimos años, la comunidad científica ha sido consciente de la importancia del desarrollo de competencias emocionales para el éxito escolar y profesional de los estudiantes.

OBJETIVO(S): Identificar los factores que influencian el abandono escolar de los estudiantes de la enseñanza superior politécnica. Analizar la relación entre las competencias emocionales y el abandono escolar de los estudiantes de la Enseñanza Superior Politécnica.

METODOLOGÍA: Estudio cuantitativo, transversal, descriptivo y correlacional. El instrumento de recolección de datos utilizada fue cuestionario sociodemográfico de los estudiantes y los padres, Enseñanza Superior Abandono de Escala razones (Ambiel, 2015) y la Escala de Competencia Emocional (Taksic', 2000), adaptado a Portugal por Faria y Santos (2006). Muestra constituida por 560 estudiantes de enseñanza superior que asisten al primer año del curso.

RESULTADOS: Un total de 560 estudiantes de educación superior asistieron al primer año del curso, en su mayoría mujeres (69.3\%), con una edad mínima de 18 años y un máximo de 30 años, lo que corresponde a un promedio de 19.76 años ( \pm 2.06 años), $36.6 \%$ del área de tecnología. El sexo influyó en la tasa de deserción escolar de los estudiantes de educación superior, y las alumnas mostraron más motivos para abandonar la escuela $(\mathrm{p}=0.010)$. Los estudiantes cuya madre es profesionalmente activa muestran más intención de abandono $(\mathrm{p}=0.035)$. La percepción emocional, la expresión emocional y la capacidad de manejar las emociones predecían la intención de abandonarla.

CONCLUSIONES: Los resultados apuntan a la necesidad de incluir en los programas de intervención contra el abandono escolar las variables de género, edad y algunas dimensiones de las competencias emocionales, con el fin de minimizar sus consecuencias, tanto para los estudiantes como para la propia sociedad.

\section{DESCRIPTORES: Competencias emocionales; Prevención del abandono; Estudiantes de enseñanza superior}

\section{ABSTRACT \\ "Emotional skills and prevention of dropout in students of poly- technic higher education"}

BACKGROUND: In recent years, the scientific community has become aware of the importance of the development of emotional competences for students' academic and professional success.

AIM: To identify the factors that influence the drop out of students of polytechnic higher education. To analyze the relation between the emotional competences and the school dropout of the students of Polytechnic Higher Education.

METHODS: Quantitative, cross-sectional, descriptive and correlational study. The data collection instrument used was a sociodemographic characterization questionnaire for students and parents, the Motivation Scale for Abandonment of Higher Education (Ambiel, 2015) and the Emotional Skills Scale (Taksic', 2000), adapted for Portugal by Faria and Santos (2006). Sample composed of 560 students of higher education attending the first year of the course.

RESULTS: A total of 560 higher education students attended the first year of the course, mostly female $(69.3 \%)$, with a minimum age of 18 years and a maximum of 30 years, corresponding to an average of 19.76 years ( \pm 2.06 years), $36.6 \%$ of the technology area. Sex influenced the dropout rate of higher education students, with female students showing more reasons for dropout $(p=0.010)$. Students whose mother is professionally active show more intention of abandonment $(p=0.035)$. Emotional perception, emotional expression and the ability to deal with emotions were predictive of intention to drop out.

CONCLUSIONS: The results point to the need to include in the intervention programs against school abandonment of the variables gender, age and some dimensions of emotional competences, in order to minimize their consequences, both for students and for society itself.

\section{KEYWORDS: Emotional competences; Prevention of abandon- ment; Students of higher education}

Submetido em 30-12-2017

Aceite em 21-03-2018

1 Doutoramento; Professora Coordenadora no Instituto Politécnico de Viseu, Escola Superior de Saúde, Viseu, Portugal, mmcferreira@gmail.com

2 Doutoramento; Professor Coordenador no Instituto Politécnico de Viseu (IPV), Escola Superior de Saúde, 3500-843 Viseu, Portugal, duarte.johnny@gmail.com

3 Agregação; Professora Coordenadora no IPV, Escola Superior de Educação, Departamento de Psicologia e Ciências da Educação, a.p.cardoso@esev.ipv.pt

4 Doutoramento; Professora Coordenadora no Instituto Politécnico de Viseu, Escola Superior de Saúde, 3500-843 Viseu, Portugal, lcabral@essv.ipv.pt

5 Agregação; Professora Coordenadora no Instituto Politécnico de Viseu, Escola Superior Agrária, 3500 - 606 Viseu, raquelguine@esav.ipv.pt

6 Doutoramento; Professora Convidada no Instituto Politécnico de Viseu, Escola Superior de Saúde, 3500-843 Viseu, Portugal, sofiamargaridacampos@gmail.com

7 Doutoramento; Professora Doutora na Universidade de Ceuma, 65065-470 São Luís, MA, Brasil, candida.alves@hotmail.com 


\section{INTRODUÇÃO}

O abandono escolar precoce é um fenómeno com drásticas consequências negativas na vida dos estudantes no ensino superior, que ficam mais expostos ao desemprego ou a empregos precários e mal remunerados e mais suscetíveis de depender dos pais e de programas sociais ao longo de toda a vida, enfrentando maior risco de pobreza e de exclusão social. Por este motivo, os países europeus assumiram o compromisso de reduzir a taxa média de abandono escolar para menos de $10 \%$ até 2020 e iniciaram um processo de cooperação política que objetiva a aprendizagem interpares e o intercâmbio de boas práticas (Baptista, 2015; Rabelo, 2017).

O Governo Português tem procurado incentivar várias instituições a desenvolverem estudos para compreender o fenómeno, como é o caso do Observatório Permanente do Abandono e Promoção do Sucesso Escolar da Universidade de Trás-os-Montes e Alto Douro, referenciado por Rabelo (2017), que concluiu que, no ano letivo 2015/2016, a maior parte dos estudantes do ensino superior que abandonaram os estudos frequentavam o $1 .^{\circ}$ ano de licenciatura ou o mestrado integrado (68\%) e os restantes $32 \%$ frequentavam os $2 .^{\circ}, 3 .^{\circ}$ e $4 .^{\circ}$ anos.

$\mathrm{O}$ abandono escolar significa que um estudante deixa a escola sem concluir o grau de ensino frequentado por outras razões que não sejam a transferência ou casos graves (Ferreira \& Fernandes, 2015). Este constitui-se como um problema complexo associado a inúmeras causas muitas vezes interligadas, podendo ser influenciado por fatores que vão de problemas pessoais e familiares, dificuldades de aprendizagem, experiências escolares negativas e situações socioeconómicas precárias, que importa aprofundar e compreender. Uma vez que as dificuldades começam precisamente no ingresso do ensino superior, delineou-se assim uma investigação com o objetivo geral de identificar os fatores que estão associados ao abandono escolar dos estudantes do $1 .^{\circ}$ ano dos estudantes do Instituto Politécnico de Viseu.

Mais especificamente, procurou-se identificar que variáveis sociodemográficas influenciam o abandono escolar dos estudantes do ensino superior; averiguar de que modo as variáveis de contexto académico influenciam o abandono escolar; identificar se existe relação entre as competências emocionais e o abandono escolar destes estudantes.

\section{METODOLOGIA}

Para o efeito, realizou-se um estudo quantitativo, transversal, descritivo e correlacional, com recurso ao inquérito por questionário. Os instrumentos de recolha de dados utilizados foram questionário de caracterização sociodemográfica dos estudantes e dos pais, a Escala performance de Aprendizagem, a Escala de motivos para abandono do ensino superior (Ambiel, 2015) e a Escala Competências Emocionais (Taksic', 2000), adaptada para a população portuguesa por Faria e Santos (2006).

\section{Participantes e Sua Caraterização}

Recorreu-se a uma amostra não probabilística por conveniência constituída por 560 estudantes do ensino superior do Instituto Politécnico de Viseu a frequentar o $1 .^{\circ}$ ano do curso, em maior percentagem da Escola Superior de Tecnologia de Viseu (36,6\%) e da Escola Superior de Educação de Viseu (30,5\%). No desenvolvimento da investigação foram salvaguardados os direitos dos participantes e os princípios éticos considerados fundamentais neste tipo de estudo.

As estatísticas da idade por sexo revelam, para a totalidade da amostra, que esta é maioritariamente feminina (69,3\%), com uma idade mínima de 18 anos e uma máxima de 30 anos, correspondendo-lhe uma média de 19,76 anos ( $\pm 2,06$ anos), e um coeficiente de variação de $21,31 \%$ sugestivo de dispersão moderada. Em relação à idade, sobressaem os estudantes mais velhos, com 20 ou mais anos de idade $(42,1 \%)$, dos quais $51,7 \%$ são do sexo masculino e $37,9 \%$ do sexo feminino. São também expressivos os percentuais registados em relação aos estudantes com 19 anos, com uma representatividade de $30,4 \%$ no total da amostra, fazendo parte deste grupo $31,5 \%$ do sexo masculino e 34,3 do sexo feminino. O grupo etário dos 18 anos representa $27,5 \%$ da amostra $(26,7 \%$ do sexo masculino vs. $27,8 \%$ do sexo feminino), resultando em diferenças estatisticamente significativas $(\mathrm{X} 2=11,880 ; \mathrm{p}=0,003)$ que se localizam entre participantes do sexo feminino e com idade de 19 anos e masculino com idade superior ou igual a 20 anos.

\section{Instrumentos de Recolha de Dados}

Para operacionalizar os objetivos definidos recorreuse ao inquérito por questionário a ser preenchido pelos próprios estudantes. Este instrumento está subdividido em várias secções. 
A primeira secção é constituída por um questionário sociodemográfico dos estudantes e pais, composta por 11 questões, 9 das quais permitem colher informação acerca dos dados pessoais dos estudantes (idade, sexo, ano de curso, $1 .^{\circ}$ ano letivo de matrícula no curso que frequenta, estatuto, benefícios sociais, deslocação da residência habitual) e 2 relativas a dados sobre os pais dos estudantes (profissão e habilitações literárias).

A segunda secção inclui a Escala de Motivos para Evasão do Ensino Superior (M-ES), composta por 67 itens relacionados com os motivos que influenciam a decisão de um aluno do ensino superior evadir-se do seu curso superior. A chave de resposta é em formato likert de cinco pontos, variando entre " 1 - muito fraco" e " 5 - muito forte". Trata-se de um inventário que avalia os motivos potenciais de estudantes ativos para deixarem seus respetivos cursos antes da conclusão. A escala utilizada neste trabalho foi adaptada, sendo que a nossa apresenta apenas 4 fatores: Fatores Organizacionais (e.g., "A instituição não oferecer nenhum programa de acompanhamento pedagógico"); Fatores de Gestão de Vida (e.g., “Trabalhar no mesmo horário das aulas”); Fatores Relacionais (e.g., "Ter uma classe social diferente dos meus colegas"); e Fatores da Profissão/Carreira (e.g., "Perceber que a atividade profissional não será tão agradável quanto eu imaginei").

O estudo de consistência interna da escala revela que os coeficientes alfa de Cronbach, por item, situamse todos acima dos 0,957. Relativamente a cada uma das subescalas os valores são de 0,900 (F1), 0,848 (F2), 0.827 (F3), 0,852 (F4). A última secção integra o Questionário de Competência Emocional (QCE) (Taksic', 2000), já adaptado para Portugal por Faria e Lima Santos (2006) e que se funda no modelo teórico de Mayer e Salovey (1997). O QCE é composto por 45 itens respondidos numa escala de Likert de 6 pontos, entre "Nunca" e "Sempre". As pontuações mais elevadas são reveladoras de maior inteligência ou competência emocional. A escala também foi adaptada para o presente estudo, sendo que a nossa, ao contrário da que foi adaptada para Portugal, apresenta 4 fatores, e não 3: F1 - Perceção emocional (e.g., "Percebo quando alguém tenta esconder os seus verdadeiros sentimentos"); F2- Expressão emocional (e.g., "Consigo descrever o meu estado emocional atual"); F3 - Capacidade de lidar com a emoção (e.g., "Procuro moderar as emoções desagradáveis e reforçar as positivas"), F4 - Investimento emocional (e.g. "Quando alguém me elogia, trabalho com maior entusiasmo"). Os alfas de Cronbach dos referidos fatores são, respetivamente, de $0,791,0,874,0,834$ e 0,684 .

\section{Análise dos Dados}

Para a análise dos dados, recorreu-se à estatística descritiva e à estatística analítica ou inferencial. A primeira permitiu calcular as frequências absolutas e percentuais, algumas medidas de tendência central, nomeadamente as médias e as medidas dispersão, como a amplitude de variação, o coeficiente de variação e o desvio padrão, bem como as medidas de forma, como a assimetria e achatamento. Para as variáveis em estudo, utilizou-se a análise univariada e bivariada. Em termos de estatística inferencial, recorreu-se a testes paramétricos e não paramétricos, designadamente aos Testes t de Student ou teste de $\mathrm{U}$ Mann Whitney usados para amostras independentes; a Análise de variância a um fator (ANOVA) ou Teste de Kruskall Wallis - usados para a comparação de médias de uma variável quantitativa (variável endógena) em três ou mais grupos de sujeitos diferentes (variável exógena - qualitativa); o Teste de qui quadrado (X2) - para o estudo de relações entre variáveis nominais. Quanto à análise bivariada, aplicou-se o teste da percentagem residual (resíduos ajustados), que nos dá as diferenças percentuais de variável a variável, muitas vezes em detrimento do teste de $\mathrm{X} 2$, pois, em muitas das variáveis em estudo, o tamanho das subamostras não possibilitava o uso do referido teste.

\section{RESULTADOS}

\section{Dados da Análise Descritiva}

Os estudantes frequentam na sua maioria a Escola Superior de Tecnologia de Viseu $(36,6 \%)$ dos quais $57,0 \%$ são do sexo masculino e $27,6 \%$ do sexo feminino. Verifica-se também que é expressiva a percentagem de estudantes da Escola Superior de Educação de Viseu (30,5\%), onde $22,1 \%$ são do sexo masculino e $34,3 \%$ do sexo feminino.

A quase a totalidade da amostra (91,4\%) admite que não goza de qualquer estatuto especial no presente não letivo, apurando-se também que a maioria $(50,9 \%)$ não possui benefícios sociais, fazendo parte deste grupo $65,7 \%$ dos estudantes do sexo masculino e $44,3 \%$ do sexo feminino, enquanto $49,1 \%$ usufruiu de benefícios sociais ( $34,3 \%$ sexo masculino vs. $55,7 \%$ sexo feminino), com diferenças estatisticamente significativas $(\mathrm{X} 2=21,772 ; \mathrm{p}=0,000)$, cujos residuais revelam que essa diferença reside entre os estudantes do sexo masculino sem benefícios sociais e os estudantes do sexo feminino com benefícios sociais no presente ano letivo. 
De salientar também o facto de que a maioria dos estudantes $(69,5 \%)$ estão deslocados da sua residência habitual, entre eles $61,6 \%$ são do sexo masculino e $72,9 \%$ do feminino, contrariamente a $30,5 \%$ que referem que não estão deslocados da sua residência habitual (sexo masculino $38,4 \%$ vs. sexo feminino $27,1 \%$ ). Resulta, daqui diferenças estatisticamente significativas (X2=7,187; $\mathrm{p}=0,007)$, situando-se essas diferenças, de acordo com os valores residuais, entre os estudantes do sexo feminino que se encontram deslocados da sua residência habitual e os estudantes do sexo masculino que não estão deslocados.

No que concerne à frequência com que os estudantes estudam, verifica-se que há um predomínio de participantes que estudam ocasionalmente $(42,7 \%)$, sendo $60,5 \%$ do sexo masculino e $34,8 \%$ do sexo feminino, secundados pelos que estudam frequentemente $(34,3 \%)$, com o sexo masculino a representar $26,7 \%$ e o feminino $37,6 \%$. Importa referir que $23,0 \%$ dos participantes estudam diariamente, sobretudo as estudantes do sexo feminino $(27,6 \%)$, com diferenças estatisticamente significativas $(\mathrm{X} 2=21,772 ; \mathrm{p}=0,000)$, cujos residuais indicam que essas diferenças se situam entre os estudantes do sexo feminino que estudam diariamente e os do sexo masculino que estudam ocasionalmente.

\section{Dados da Análise Inferencial}

Constata-se que são os estudantes do sexo feminino os que apresentam valores médios mais elevados na escala de motivos de evasão do ensino superior, com diferença estatisticamente significativa no abandono escolar global $(\mathrm{p}=0,010)$ (Tabela 1$)$.

Tabela 1 - Teste $t$ para diferença de médias entre o sexo e o abandono escolar

\begin{tabular}{|c|c|c|c|c|c|c|}
\hline Sexo & Masc & lino & Femi & nino & & \\
\hline $\begin{array}{l}\text { Abandono } \\
\text { Escolar }\end{array}$ & Média & $\mathrm{Dp}$ & Média & $\mathrm{Dp}$ & $\mathrm{t}$ & $\mathrm{p}$ \\
\hline $\begin{array}{l}\text { Dimensão orga- } \\
\text { nizacional }\end{array}$ & 32,51 & 20,50 & 34,66 & 19,14 & $-1,199$ & 0,231 \\
\hline $\begin{array}{l}\text { Dimensão } \\
\text { gestão de vida }\end{array}$ & 35,99 & 21,85 & 45,39 & 20,77 & $-4,860$ & 0,000 \\
\hline $\begin{array}{l}\text { Dimensão } \\
\text { relacional }\end{array}$ & 23,23 & 19,38 & 23,79 & 17,80 & $-0,334$ & 0,739 \\
\hline $\begin{array}{l}\text { Dimensão pro- } \\
\text { fissão/carreira }\end{array}$ & 38,50 & 19,62 & 41,92 & 17,37 & $-2,065$ & 0,039 \\
\hline $\begin{array}{l}\text { Abandono es- } \\
\text { colar (global) }\end{array}$ & 33,00 & 17,68 & 36,87 & 15,74 & $-2,579$ & 0,010 \\
\hline
\end{tabular}

Quanto à relação entre as habilitações literárias da mãe e o abandono escolar, como exposto na Tabela 2 , verifica-se que os estudantes cujas mães possuem o ensino superior revelam valores médios mais elevados em quase todas as dimensões do abandono escolar, excetuando a dimensão profissão/carreira, onde sobressaem os estudantes cujas mães têm menores habilitações académicas, no entanto, não se registam diferenças estatisticamente significativas.

Tabela 2 -ANOVA para diferença de médias entre as habilitações literárias da mãe e o abandono escolar

\begin{tabular}{|l|c|c|c|c|c|c|c|c|}
\hline $\begin{array}{l}\text { Habilitações } \\
\text { da mãe }\end{array}$ & \multicolumn{2}{|c|}{$\begin{array}{c}\text { Até ensino } \\
\text { básico }\end{array}$} & \multicolumn{2}{|c|}{$\begin{array}{c}\text { Ensino } \\
\text { secundário }\end{array}$} & \multicolumn{2}{|c|}{$\begin{array}{c}\text { Ensino } \\
\text { superior }\end{array}$} & t & $\mathrm{p}$ \\
\cline { 1 - 5 } $\begin{array}{l}\text { Abandono } \\
\text { Escolar }\end{array}$ & $\begin{array}{c}\text { Mé- } \\
\text { dia }\end{array}$ & Dp & $\begin{array}{c}\text { Mé- } \\
\text { dia }\end{array}$ & Dp & $\begin{array}{c}\text { Mé- } \\
\text { dia }\end{array}$ & Dp & & \\
\hline $\begin{array}{l}\text { Dimensão } \\
\text { organizacio- } \\
\text { nal }\end{array}$ & 33,72 & 19,94 & 33,82 & 19,33 & 34,45 & 19,75 & 0,067 & 0,935 \\
\hline $\begin{array}{l}\text { Dimensão } \\
\text { gestão de } \\
\text { vida }\end{array}$ & 43,54 & 21,77 & 41,88 & 21,48 & 41,99 & 21,59 & 0,366 & 0,694 \\
\hline $\begin{array}{l}\text { Dimensão } \\
\text { relacional }\end{array}$ & 22,53 & 17,02 & 23,88 & 18,97 & 25,00 & 19,36 & 0,815 & 0,443 \\
\hline $\begin{array}{l}\text { Dimensão } \\
\text { profissão/ } \\
\text { carreira }\end{array}$ & 41,40 & 18,06 & 40,55 & 17,67 & 40,65 & 19,09 & 0,130 & 0,878 \\
\hline $\begin{array}{l}\text { Aban- } \\
\text { dono escolar } \\
\text { (global) }\end{array}$ & 35,76 & 16,1 & 35,4 & 16,4 & 35,9 & 17,1 & 0,03 & 0,96 \\
\hline
\end{tabular}

A profissão da mãe teve influência no abandono escolar, sendo os estudantes cujas mães se encontras ativas profissionalmente aqueles que manifestam valores médios mais elevados em quase todas as dimensões do abandono escolar, com exceção da dimensão gestão de vida, onde sobressaem os estudantes cujas mães não estão no ativo em termos profissionais, verificando-se que há diferença estatisticamente significativa em relação à dimensão profissão/carreira $(\mathrm{p}=0,035)$ (Tabela 3).

Tabela 3 - Teste Mann-Whitney para a relação entre a profissão da mãe e o abandono escolar

\begin{tabular}{|l|c|c|c|c|}
\hline \multicolumn{1}{|c|}{ Profissão da mãe } & Ativa & Não ativa & \multirow{2}{*}{ UMW } & $\mathrm{p}$ \\
\hline Abandono Escolar & $\mathrm{OM}$ & $\mathrm{OM}$ & & 0,062 \\
\cline { 1 - 3 } $\begin{array}{l}\text { Dimensão orga- } \\
\text { nizacional }\end{array}$ & 285,16 & 255,51 & 25193,000 & \\
\hline $\begin{array}{l}\text { Dimensão gestão de } \\
\text { vida }\end{array}$ & 276,37 & 283,13 & 27519,500 & 0,670 \\
\hline Dimensão relacional & 280,30 & 270,78 & 27239,500 & 0,549 \\
\hline $\begin{array}{l}\text { Dimensão profissão/ } \\
\text { carreira }\end{array}$ & 286,08 & 252,61 & 24805,000 & 0,035 \\
\cline { 1 - 2 } $\begin{array}{l}\text { Abandono escolar } \\
\text { (global) }\end{array}$ & 283,70 & 260,08 & 25805,500 & 0,137 \\
\hline
\end{tabular}


A primeira dimensão do abandono escolar a ser estudada através da regressão múltipla foi a dimensão organizacional. As correlações obtidas com as diferentes variáveis em análise indicam valores correlacionais positivos, à exceção do sexo $(\mathrm{r}=-0,051)$, que estabelece uma relação inversa com a dimensão organizacional. Ressalva-se também que só se encontra relevância estatística na perceção emocional $(\mathrm{p}=0.001)$, na expressão emocional $(p=0,044)$ e no investimento emocional $(\mathrm{p}=0,035)$.

A variável preditora da dimensão organizacional é a perceção emocional, que explica $0,1 \%$ da variação, sendo a variância explicada ajustada de $0,1 \%$. O erro padrão de regressão é 19,42 e o teste $F(f=10,006 ; p=0,002)$ e o valor de $\mathrm{t}(\mathrm{t}=5,609 ; \mathrm{p}=0.000)$, apresentando significância estatística, o que sugere que a variável que entrou no modelo de regressão tem poder explicativo sobre a dimensão organizacional.

Pelos coeficientes padronizados beta, infere-se que a perceção emocional estabelece uma relação direta com a dimensão organizacional, sugerindo que quanto mais perceção emocional os estudantes têm menos percecionam a dimensão organizacional como fator de abandono escolar.

A segunda dimensão do abandono escolar a ser estudada através da regressão múltipla foi a dimensão gestão de vida. As correlações obtidas com as diferentes variáveis em análise indicam valores correlacionais positivos, à exceção do sexo $(r=-0,202)$ e idade $(r=-$ 0,040), que estabelecem uma relação inversa com a dimensão gestão de vida. Regista-se relevância estatística no sexo $(p=0.000)$, na expressão emocional $(p=0,0001)$ e na capacidade de lidar com a emoção $(p=0,021)$.

As variáveis preditoras da dimensão gestão de vida são o sexo e a expressão emocional, que explicam 0,6\% da variação, sendo a variância explicada ajustada de $0,5 \%$. O erro padrão de regressão é 20,89 e o teste $\mathrm{F}$ $(\mathrm{f}=12,647 ; \mathrm{p}=0,000)$ e o valor de $\mathrm{t}(\mathrm{t}=12,096 ; \mathrm{p}=0.000)$, apresentando significância estatística, o que sugere que as variáveis que entraram no modelo de regressão têm poder explicativo sobre a dimensão gestão de vida.

Pelos coeficientes padronizados beta, infere-se que a expressão emocional estabelece uma relação direta com a dimensão gestão de vida, sugerindo que quanto mais expressão emocional os estudantes têm menos percecionam a dimensão gestão de vida como fator de abandono escolar, enquanto o sexo estabelece uma relação inversa, indicando que independentemente do sexo os estudantes mais perceção têm da dimensão gestão de vida como potencial fator de abandono escolar. A terceira dimensão do abandono escolar a ser estudada através da regressão múltipla foi a dimensão relacional. As correlações obtidas com as diferentes variáveis em análise indicam valores correlacionais negativos apenas para a idade $(\mathrm{r}=0,025)$ e expressão emocional $(\mathrm{r}=0,020)$, que estabelecem uma relação inversa com a dimensão relacional, tendo as restantes variáveis estabelecido uma relação inversa. Regista-se relevância estatística apenas na capacidade de lidar com a emoção $(\mathrm{p}=0,001)$.

As variáveis preditoras da dimensão relacional são a expressão emocional e a capacidade de lidar com a emoção, que explicam $0,3 \%$ da variação, sendo a variância explicada ajustada de $0,2 \%$. O erro padrão de regressão é 18,04 e o teste $\mathrm{F}(\mathrm{f}=7,855 ; \mathrm{p}=0,005)$ e o valor de $t(t=9,151 ; p=0.000)$, apresentando significância estatística, o que sugere que as variáveis que entraram no modelo de regressão têm poder explicativo sobre a dimensão relacional.

Pelos coeficientes padronizados beta, infere-se que a expressão emocional estabelece uma relação inversa com a dimensão relacional, sugerindo que quanto menos expressão emocional os estudantes têm maior é perceção da dimensão relacional como fator de abandono escolar, enquanto a capacidade de lidar com a emoção estabelece uma relação direta, indicando que quanto menos capacidade de lidar com a vida têm os estudantes mais perceção têm da dimensão relacional como latente fator de abandono escolar.

A quarta dimensão do abandono escolar a ser estudada através da regressão múltipla foi a dimensão profissão/carreira. As correlações obtidas com as diferentes variáveis em análise indicam valores correlacionais negativos para todas as variáveis. Regista-se relevância estatística apenas no sexo $(\mathrm{p}=0,020)$.

A variável preditora da dimensão profissão/carreira é o sexo, que explica $0,8 \%$ da variação, sendo a variância explicada ajustada de $0,0 \%$. O erro padrão de regressão é 10,09 e o teste $F(f=4,264 ; \mathrm{p}=0,039)$ e o valor de $\mathrm{t}(\mathrm{t}=45,633 ; \mathrm{p}=0.000)$, apresentando significância estatística, o que sugere que a variável que entrou no modelo de regressão tem poder explicativo sobre a dimensão profissão/carreira.

Pelos coeficientes padronizados beta, infere-se que o sexo estabelece uma relação inversa com a dimensão profissão/carreira, sugerindo que independentemente do sexo maior é perceção da dimensão profissão/carreira como fator de abandono escolar. 
$\mathrm{Na}$ Tabela 4 encontram-se as correlações obtidas com o abandono escolar global e as diferentes variáveis em análise, cujos resultados indicam que valores correlacionais negativos para o sexo $(\mathrm{r}=-0,109)$ e para a idade $(\mathrm{r}=-0,006)$, estabelecendo uma relação direta com as restantes variáveis. Regista-se relevância estatística apenas no sexo $(\mathrm{p}=0,005)$.

Tabela 4 - Correlações de Pearson entre variáveis independentes e abandono escolar global

\begin{tabular}{|l|c|c|}
\hline Variáveis & $\mathbf{R}$ & $\mathbf{P}$ \\
\hline Sexo_dummy & $-0,109$ & 0,005 \\
\hline Idade & $-0,006$ & 0,443 \\
\hline Perceção emocional & 0,052 & 0,108 \\
\hline Expressão Emocional & 0,067 & 0,056 \\
\hline $\begin{array}{l}\text { Capacidade de lidar com a } \\
\text { emoção }\end{array}$ & 0,000 & 0,496 \\
\hline Investimento Emocional & 0,036 & 0,197 \\
\hline
\end{tabular}

A variável preditora do abandono escolar global é o sexo, que explica $0,1 \%$ da variação, sendo a variância explicada ajustada de $0,1 \%$. O erro padrão de regressão é 16,36 e o teste $F(f=6,651 ; p=0,010)$ e o valor de $t(t=44,386 ; p=0.000)$, apresentando significância estatística, o que sugere que a variável que entrou no modelo de regressão tem poder explicativo sobre o abandono escolar global. Pelos coeficientes padronizados beta, infere-se que o sexo estabelece uma relação inversa com o abandono escolar, sugerindo que independentemente do sexo maior é perceção que os estudantes têm do abandono escolar.

\section{DISCUSSÃO}

Os dados apresentados indicam que apenas o sexo se assumiu como variável sociodemográfica que interferiu estatisticamente no abandono escolar dos estudantes do ensino superior, sendo os estudantes do sexo feminino os que revelam mais propensão a evadir-se do curso, ou seja, apresentam mais motivos para o abandono escolar (abandono escolar global $\mathrm{p}=0,010)$. Perante este resultado, trabalhar a perspetiva de género nos recursos de ensino e aprendizagem constitui um domínio relevante e um desafio para as instituições de ensino superior. Também Cavaco (2015) no estudo que realizou alerta para a necessidade das políticas públicas de educação e formação incorporarem a dimensão de género nas estratégias de resposta que visam promover o sucesso educativo.

Verificou-se que apenas a profissão da mãe está associada ao abandono escolar, sendo os estudantes cujas mães se encontras ativas profissionalmente os que manifestam valores médios mais elevados em quase todas as dimensões do abandono escolar, com exceção da dimensão gestão de vida, onde sobressaem os estudantes em que as mães não estão no ativo em termos profissionais (dimensão profissão/carreira $\mathrm{p}=0,035)$. Tal poderá sugerir uma menor disponibilidade das mães para apoiar e comunicar eficazmente com os filhos nesta fase exigente de transição da vida escolar, que poderá refletir-se negativamente na adaptação ao ensino superior.

No que se refere aos resultados da relação entre o abandono escolar com as variáveis sociodemográfica e com as competências emocionais, verificou-se que a perceção emocional estabelece uma relação direta com a dimensão organizacional, sugerindo que quanto mais perceção emocional os estudantes têm menos percecionam a dimensão organizacional como fator de abandono escolar. A expressão emocional estabelece uma relação direta com a dimensão gestão de vida, sugerindo que quanto mais expressão emocional os estudantes têm menos percecionam a dimensão gestão de vida como fator de abandono escolar, enquanto o sexo estabelece uma relação inversa, indicando que, independentemente do sexo, os estudantes mais perceção têm da dimensão gestão de vida como potencial fator de abandono escolar. A expressão emocional também estabelece uma relação inversa com a dimensão relacional, sugerindo que quanto menos expressão emocional os estudantes têm maior é perceção da dimensão relacional como fator de abandono escolar, enquanto a capacidade de lidar com a emoção estabelece uma relação direta, indicando que quanto menos capacidade de lidar com a vida têm os estudantes mais perceção têm da dimensão relacional como latente fator de abandono escolar. $\mathrm{O}$ sexo estabelece uma relação inversa com a dimensão profissão/carreira e com o abandono escolar global, sugerindo que, independentemente do sexo, maior é perceção da dimensão profissão/carreira como fator de abandono escolar e do abandono escolar na sua globalidade. De igual modo, Silva e Duarte (2012), num estudo realizado com estudantes do curso de licenciatura em Enfermagem da Escola Superior de Saúde de Viseu, verificaram que a inteligência emocional influencia o sucesso escolar. Os autores salientam que saber mobilizar as emoções ao serviço de um objetivo e concentrar a sua atenção para a competência e para a criatividade é essencial para o sucesso na vida. 
Num outro estudo com estudantes do ensino superior, Fernandez, Salamonson e Griffiths (2012) referem que as competências emocionais e as estratégias de aprendizagem se relacionam positivamente com o sucesso académico, assumindo-se como um preditor abandono escolar, caso os estudantes não tenham pensamento crítico, uma aprendizagem entre pares e se sintam motivados. $\mathrm{O}$ mesmo estudo revela também que o pensamento crítico, uma adequada gestão do tempo e a motivação estão relacionados com o sucesso académico e, consequentemente, com o abandono escolar.

\section{CONCLUSÃO}

O sucesso e o abandono escolar constituem-se como temáticas de relevante interesse para todos os agentes educativos, instituições escolares, estudantes, pais, professores. Assim, torna-se importante compreender os fatores que poderão influenciar o sucesso académico no ensino superior, tendo em conta as competências emocionais e prevenção do abandono.

O presente estudo revelou que o sexo o abandono escolar dos estudantes do ensino superior, sendo os estudantes do sexo feminino os que revelam mais propensão a evadir-se do curso, ou seja, apresentam mais motivos para o abandono escolar; de salientar também que a profissão da mãe teve influência no abandono escolar, sendo os estudantes cuja mãe se encontra ativa profissionalmente os que manifestam valores médios mais elevados em quase todas as dimensões do abandono escolar, com exceção da dimensão gestão de vida, onde sobressaem os estudantes que a mãe não está no ativo em termos profissionais.

No que se refere aos resultados da relação entre o abandono escolar, variáveis sociodemográfica e competências emocionais, concluiu-se que quanto mais perceção emocional os estudantes têm menos percecionam a dimensão organizacional como fator de abandono escolar; quanto mais expressão emocional os estudantes têm menos percecionam a dimensão gestão de vida como fator de abandono escolar; independentemente do sexo, os estudantes apresentam mais perceção da dimensão gestão de vida como potencial fator de abandono escolar; quanto menos expressão emocional os estudantes têm, maior é a perceção da dimensão relacional como fator de abandono escolar; quanto menos capacidade de lidar com a vida têm os estudantes, mais perceção têm da dimensão relacional como latente fator de abandono escolar; independentemente do sexo, maior é perceção da dimensão profissão/carreira como fator de abandono escolar e do abandono escolar na sua globalidade.

\section{IMPLICAÇÕES PARA A PRÁTICA CLÍNICA}

Os resultados apontam para a necessidade de serem implementadas medidas suscetíveis de prevenir ou reduzir o abandono escolar dos estudantes do ensino superior, nomeadamente com a inclusão nos programas de intervenção de medidas tendentes a minimizar a influência negativa das variáveis sexo (trabalhar as questões de género), idade e algumas dimensões das competências emocionais. Para isso, é fundamental o esforço por parte de todos os agentes educativos, incluindo os profissionais de enfermagem, assumido de forma transversal e passando por várias vertentes, começando pela sensibilização da sociedade para a questão, fazendo deste combate uma prioridade. Esta deve começar precocemente, ou seja, sugere-se uma maior intervenção em contexto de ensino secundário, sensibilizando os alunos para a escolha racional do curso em que querem ingressar, para que não façam uma escolha errada e que os leve ao consequente abandono escolar aquando do ingresso no ensino superior.

O combate ao abandono escolar é indiscutivelmente um dos caminhos mais relevantes a nível do aumento da qualificação dos cidadãos. Este fenómeno implica a necessidade de se consolidarem conhecimentos, metodologias de estudo e estratégias de intervenção, de modo a evitar-se a saída precoce de estudantes do ensino superior. Por isso, este deve continuar a ser alvo de crescente interesse, da elaboração de trabalhos de investigação e alvo de reflexão e debate. As instituições de ensino superior, os representantes dos estudantes, o próprio Governo e outras entidades do setor devem debruçar-se mais sobre esta problemática e sobre as suas múltiplas dimensões, em prol quer do sucesso e bem-estar dos estudantes, quer do desenvolvimento da própria sociedade.

\section{REFERÊNCIAS BIBLIOGRÁFICAS}

Ambiel, R. A. M. (2015). Construção da escala de motivos para evasão do ensino superior. Avaliação Psicológica, 14 (1), 41-52. Disponível em: http://pepsic.bvsalud.org/scielo.php?script=sci_arttext\&pid $=$ S1677-04712015000100006 
Baptista, J. O. (2015). Indicadores de transferência e de abandono no ensino superior português. Lisboa: Direção-Geral de Estatísticas da Educação e Ciência (DGEEC).

Cavaco, C. (Coord.). (2015). Abandono e insucesso escolar: Construir uma perspetiva de género: Relatório final. Universidade de Lisboa. Disponível em https:// conversamos.wordpress.com/2017/02/22/abandonoe-insucesso-escolar-construir-uma-perspetiva-degenero/

Faria, L., \& Lima Santos, N. (2006). Competência emocional: Adaptação do emotional skills and competence questionnaire (ESCQ). In C. Machado, L. Almeida, M. A. Guisande, M. Gonçalves, \& V. Ramalho (Coords.), Actas das XI Conferência Internacional e Avaliação Psicológica: Formas e contextos (pp. 349356). Braga: Psiquilíbrios Edições.

Fernandez, R., Salamonson, Y., \& Griffiths, R. (2012). Emotional intelligence as a predictor of academic performance in first-year accelerated graduate entry nursing students. Journal of Clinical Nursing, 21 (23-24), 3485-3492. doi: 10.1111/j.1365-2702.2012.04199.x.
Ferreira, F., \& Fernandes, P. (2015). Fatores que influenciam o abandono no ensino superior e iniciativas para a sua prevenção o olhar de estudantes. Educação, Sociedade \& Culturas, 45, 177-197. Disponível em: https://repositorio-aberto.up.pt/bitstream/10216/82680/2/117607.pdf

Mayer, J. D., \& Salovey, P. (1997). What is emotional intelligence? In P. Salovey, \& D. J. Sluyter (Eds.), Emotional development and emotional intelligence: Educational implications (pp. 3-34). New York: Harper Collins.

Rabelo, R. (2017). Orientação vocacional é uma das principais causas de abandono no Ensino Superior. Disponível em http://www.utad.pt/vPT/Area2/noticias/Paginas/2017/noticias_fevereiro/orientacao_vocacional.aspx

Silva, D. M., \& Duarte, J.C. (2012). Sucesso escolar e inteligência emocional. Millenium, 42, 67-84. Disponível em: http://www.ipv.pt/Millenium/Millenium42/6.pdf 